\title{
EVALUASI TINGKAT PELAYANAN JALUR PEJALAN KAKI DI JALAN BRAGA BANDUNG
}

\author{
Antono Damayanto \\ Program Studi Teknik Sipil \\ Universitas Jenderal Achmad Yani \\ Jln. Ters. Jend. Sudirman, Cimahi \\ antono@ymail.com
}

\author{
Gilang Rahmat \\ Program Studi Teknik Sipil \\ Universitas Jenderal Achmad Yani \\ Jln. Ters. Jend. Sudirman, Cimahi \\ gilangrsutanto69@gmail.com
}

\author{
Reza Ramdhan \\ Program Studi Teknik Sipil \\ Universitas Jenderal Achmad Yani \\ Jln. Ters. Jend. Sudirman, Cimahi \\ rezaramdhan07@gmail.com
}

\begin{abstract}
A facility related to human travel is a pedestrian path or sidewalk. Apart from being an important facility, pedestrian paths are useful for social functions, namely as a meeting place for several individuals. The purpose of this study is to evaluate the level of service of the pedestrian path on Jalan Braga, Bandung. The method used is the methods of Greenshields and Greenberg. This study shows that, based on flow and space, the level of service varies from A to C. Meanwhile, based on speed, the level of service is E and F. Because Jalan Braga is a tourist area, speed is not a factor, so the level of service for the pedestrian path on this road is C.
\end{abstract}

Keywords: pedestrians; pedestrian paths; service stays; currents; density; speed.

\begin{abstract}
Abstrak
Suatu fasilitas yang berhubungan dengan perjalanan manusia adalah jalur pejalan kaki atau trotoar. Selain merupakan fasilitas yang penting, jalur pejalan kaki bermanfaat untuk fungsi sosial, yaitu sebagai tempat pertemuan beberapa individu. Tujuan studi ini adalah mengevaluasi tingkat pelayanan jalur pejalan kaki di Jalan Braga, Bandung. Metode yang digunakan adalah metode-metode Greenshields dan Greenberg. Studi ini menunjukkan bahwa, berdasarkan arus dan ruang, tingkat pelayanan bervariasi antara A hingga C. Sedangkan berdasarkan kecepatan, tingkat pelayanan adalah E dan F. Karena Jalan Braga merupakan kawasan wisata, kecepatan bukan merupakan, sehingga tingkat pelayanan jalur pejalan kaki di jalan ini adalah C.
\end{abstract}

Kata-kata kunci: pejalan kaki; jalur pejalan kaki; tingkat pelayanan; arus; kepadatan; kecepatan.

\section{PENDAHULUAN}

Suatu fasilitas yang terkait dengan perjalanan manusia adalah trotoar atau jalur untuk pejalan kaki. Fasilitas ini merupakan fasilitas penting, karena selain untuk orang berjalan dari satu area ke area lain, juga bermanfaat untuk memenuhi fungsi sosial, yaitu sebagai tempat pertemuan beberapa individu.

Menurut Preiser et al (1991), karakteristik pejalan kaki memiliki kesamaan dengan karakteristik pergerakan lalu lintas yang saling berhubungan, yaitu arus, kecepatan, dan kepadatan. Bila arus meningkat, kecepatan akan menurun. Selain itu, bila kepadatan meningkat, arus akan meningkat, tetapi setelah arus maksimum tercapai, arus akan menurun bila kepadatan meningkat, hingga pada saat kepadatan maksimum tercapai, kecepatan akan sama dengan nol.

Karakteristik pejalan kaki dipengaruhi oleh sifat manusia. Keinginan manusia merupakan sifat utama manusia yang membentuk pola pergerakan arus pejalan kaki, misalnya keinginan berjalan dengan perlahan atau santai, berjalan dengan cepat atau tergesagesa, atau berjalan seorang diri atau berkelompok. 
Jalan Braga adalah suatu jalan di Bandung yang ramai dikunjungi orang, karena merupakan objek wisata Kota Bandung. Studi ini bertujuan untuk mengevaluasi karakteristik pejalan kaki dan tingkat pelayanan jalur pejalan kaki di Jalan Braga tersebut.

\section{METODOLOGI PENELITIAN}

Evaluasi tingkat pelayanan jalur pejalan kaki pada studi ini dilakukan dengan menggunakan 2 metode, yaitu Metode Greenshields dan Metode Greenberg. Bagan alir penelitian dapat dilihat pada Gambar 1.

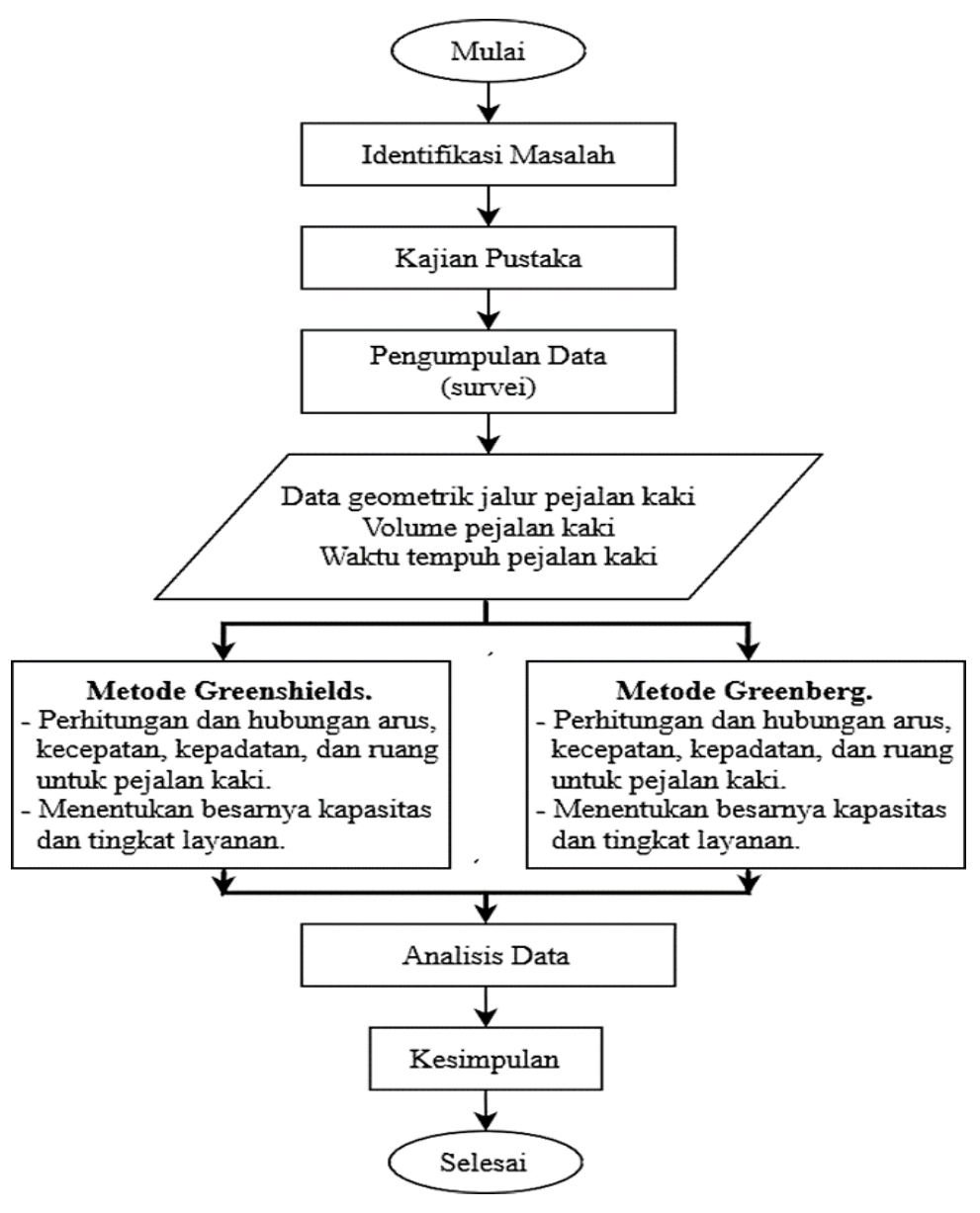

Gambar 1 Bagan Alir Penelitian

\section{PEMBAHASAN}

\section{Lokasi Penelitian}

Lokasi penelitian adalah Jalan Braga, yang terletak di Kota Bandung, seperti yang ditunjukkan pada Gambar 1. Tipikal potongan melintang Jalan Braga dapat dilihat pada Gambar 2. 


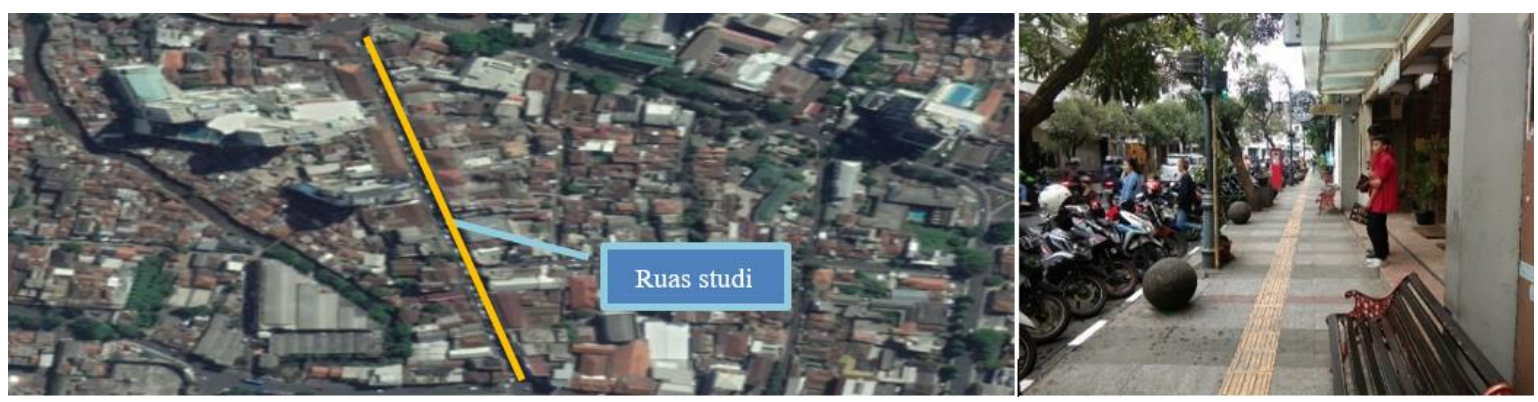

Gambar 2 Lokasi Penelitian

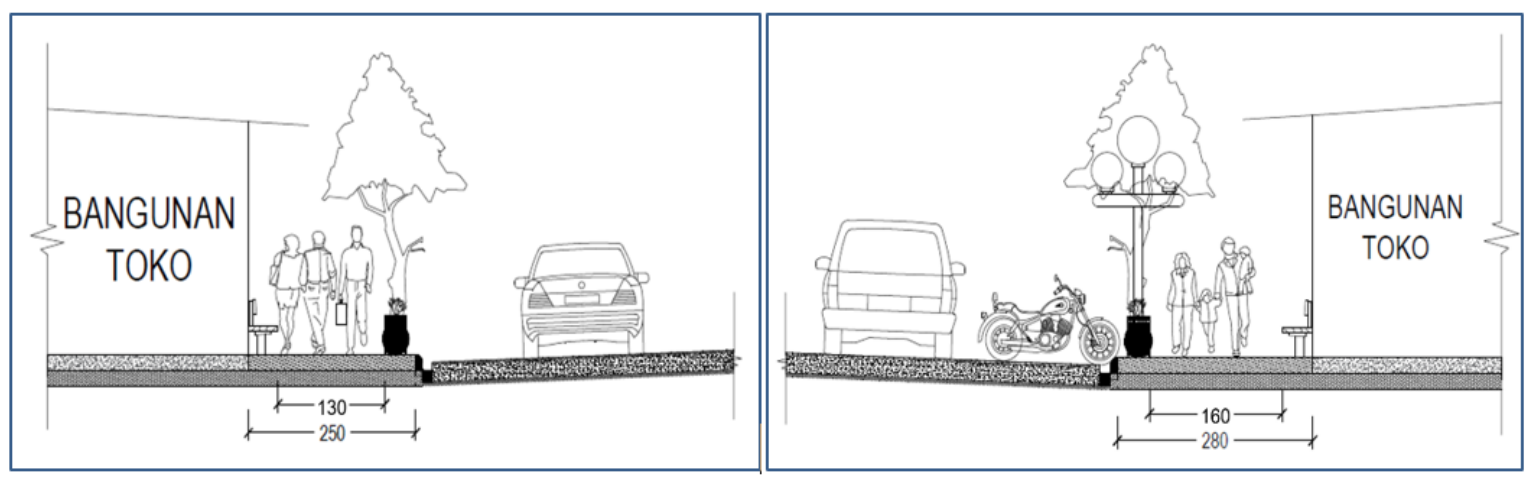

Gambar 3 Potongan Melintang Jalur Pejalan Kaki

\section{Arus, Kecepatan, dan Kepadatan Pejalan kaki}

Dari pengamatan lapangan diperoleh lebar efektif jalur pejalan kaki yang terkecil adalah 1,3 meter. Dari pengolahan data didapat jumlah pejalan kaki dua arah pada waktu puncak, dengan interval waktu pengamatan 5 menit, adalah 32 pejalan kaki. Dengan demikian didapat arus pejalan kaki rata-rata adalah 4,92 pejalan kaki/m/menit.

Kecepatan pejalan kaki pada jam puncak dihitung dengan menggunakan rumus:

$$
v=\frac{l}{t}=\frac{600}{t}
$$

dengan:

$l=\operatorname{Jarak}(\mathrm{m})$

$t=$ Waktu (menit)

Dari data yang ada didapat kecepatan pejalan kaki rata-rata adalah $61,33 \mathrm{~m} / \mathrm{menit}$.

Tingkat kepadatan pejalan kaki dihitung dengan menggunakan rumus:

$$
D=\frac{Q}{V s}
$$

dengan:

$V s=$ kecepatan rata-rata pejalan kaki

$Q=$ arus pejalan kaki 
Dengan menggunakan data yang ada didapat kepadatan pejalan kaki adalah 0,08 pejalan $\mathrm{kaki} / \mathrm{m}^{2}$.

Dengan menggunakan hasil perhitungan yang telah dilakukan, diperoleh ruang untuk pejalan kaki, yang dihitung dengan rumus:

$$
S=\frac{V s}{Q}=\frac{1}{D}
$$

dengan:

$D=$ kepadatan (pejalan kaki $\left./ \mathrm{m}^{2}\right)$

$S=$ ruang pejalan kaki $\left(\mathrm{m}^{2} /\right.$ pejalan kaki)

Dengan demikian diperoleh ruang untuk pejalan kaki adalah 12,46 m²/pejalan kaki.

\section{Metode Greenshields}

Hubungan antara Kecepatan (Vs) dengan Kepadatan (D) pejalan kaki disajikan pada Gambar 4. Terlihat bahwa bila kepadatan semakin tinggi, kecepatan akan semakin rendah. Hubungan antara kecepatan dan kepadatan adalah:

$$
\mathrm{Vs}=63,15-58,94 \mathrm{D}
$$

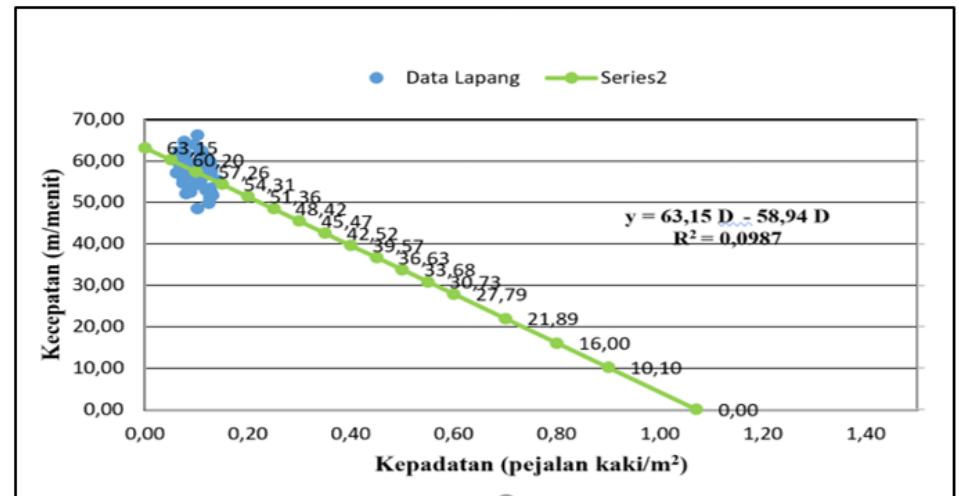

Gambar 4 Hubungan Kecepatan (Vs) dengan Kepadatan (D)

Gambar 5 menunjukkan hubungan antara arus dengan kepadatan pejalan kaki. Terlihat bahwa peningkatan arus pejalan kaki akan menyebabkan kepadatan bertambah, tetapi setelah arus maksimum tercapai, peningkatan kepadatan diikuti oleh penurunan arus, karena ruang gerak semakin sempit dengan meningkatnya kepadatan. Hubungan antara arus dan kepadatan pejalan kaki adalah:

$$
Q=63,15 \mathrm{D}-58,94 \mathrm{D}^{2}
$$

Gambar 6 menunjukkan hubungan antara arus dengan kecepatan pejalan kaki. Bila terjadi peningkatan arus pejalan kaki, kecepatan pejalan kaki mengecil sampai titik arus maksimum tercapai. Hubungan antara Arus dan kecepatan pejalan kaki adalah:

$$
\mathrm{Q}=1,071 \mathrm{Vs}-0.017 \mathrm{Vs}^{2}
$$




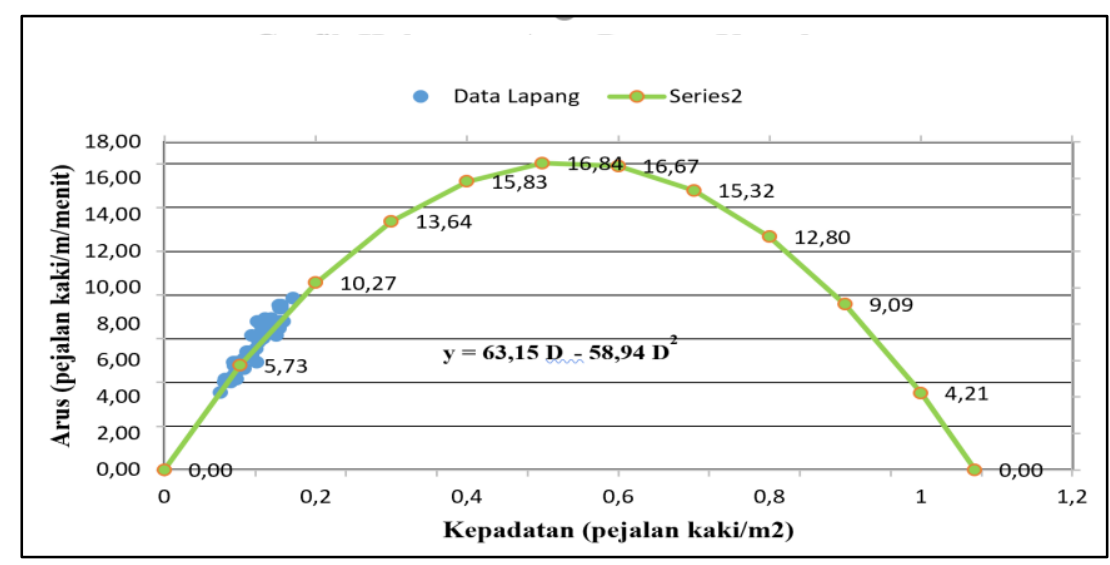

Gambar 5 Hubungan Arus (Q) dengan Kepadatan (D)

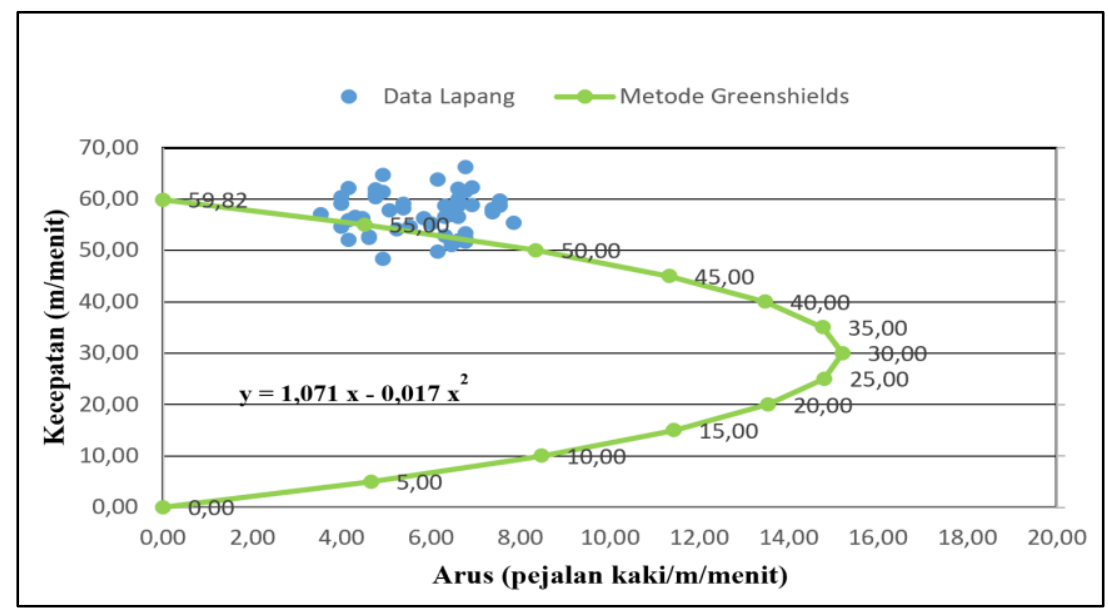

Gambar 6 Hubungan Arus (Q) dengan Kecepatan (Vs)

Berdasarkan metode Greenshields, karakteristik jalur pejalan kaki pada kondisi maksimum adalah kecepatan maksimum $(\mathrm{Vm})$ sebesar 31,57 m/min, arus maksimum $(\mathrm{Qm})$ adalah 16,92 pejalan $\mathrm{kaki} / \mathrm{m} / \mathrm{min}$, kepadatan maksimum (D) adalah 0,54 pejalan $\mathrm{kaki} / \mathrm{m}^{2}$, dan ruang maksimum $(\mathrm{Sm})$ adalah $1,85 \mathrm{~m}^{2} /$ pejalan kaki.

\section{Metode Greenberg}

Gambar 7 menunjukkan hubungan antara kecepatan dan kepadatan pejalan kaki. Bila kepadatan meningkat, kecepatan berkurang, karena meningkatnya kepadatan pejalan kaki berarti pejalan kaki memiliki ruang yang semakin kecil atau semakin sempit. Hubungan antara kecepatan dan kepadatan pejalan kaki adalah:

$$
\mathrm{Vs}=44,44-12.68 \ln \mathrm{D}
$$




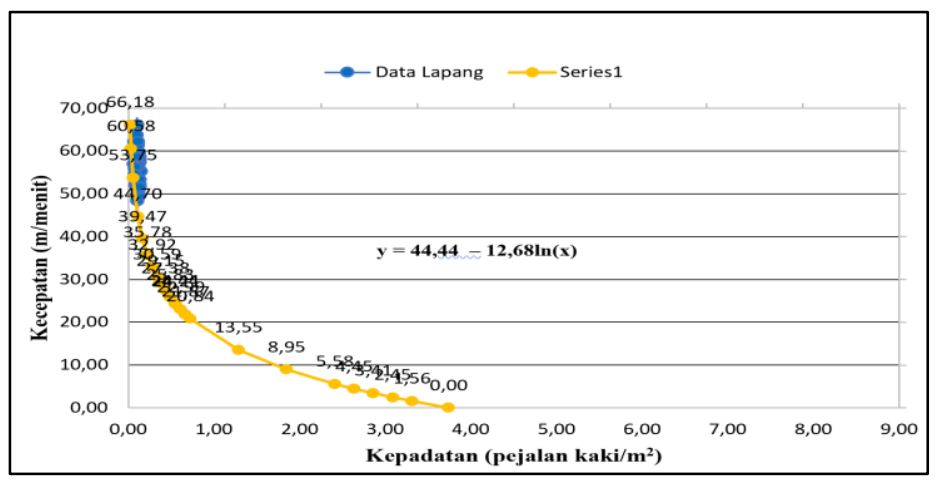

Gambar 7 Hubungan Kecepatan (Vs) dengan Kepadatan (D)

Hubungan antara arus dan kepadatan pejalan kaki dapat dilihat pada Gambar 8 . Hubungan antara arus dan kepadatan pejalan kaki adalah:

$$
\mathrm{Q}=44,44 \mathrm{D}-12,68 \ln \mathrm{D}^{2}
$$

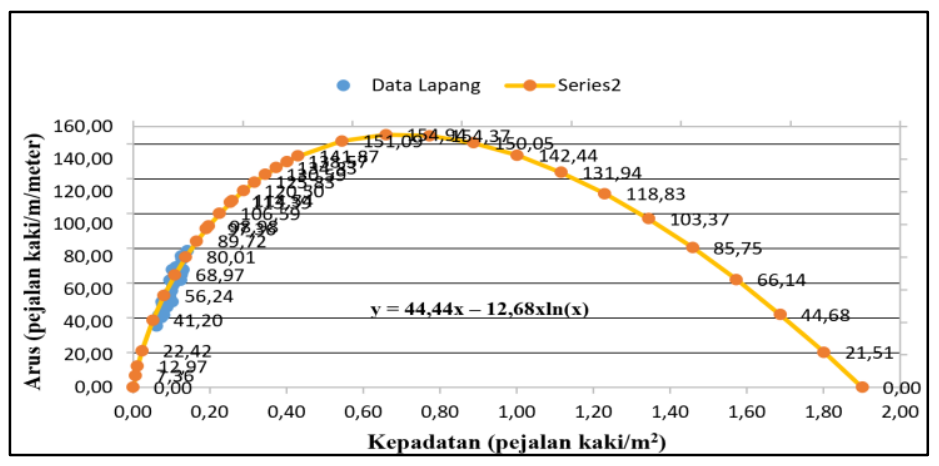

Gambar 8 Hubungan Arus (Q) dengan Kepadatan (D)

Pada Gambar 9 disajikan hubungan antara arus dan kecepatan pejalan kaki. Persamaan yang menunjukkan hubungan antara arus dan kecepatan pejalan kaki adalah:

$$
C=0,7043 \mathrm{Vs} . e^{-\mathrm{Vs} / 0,079}
$$

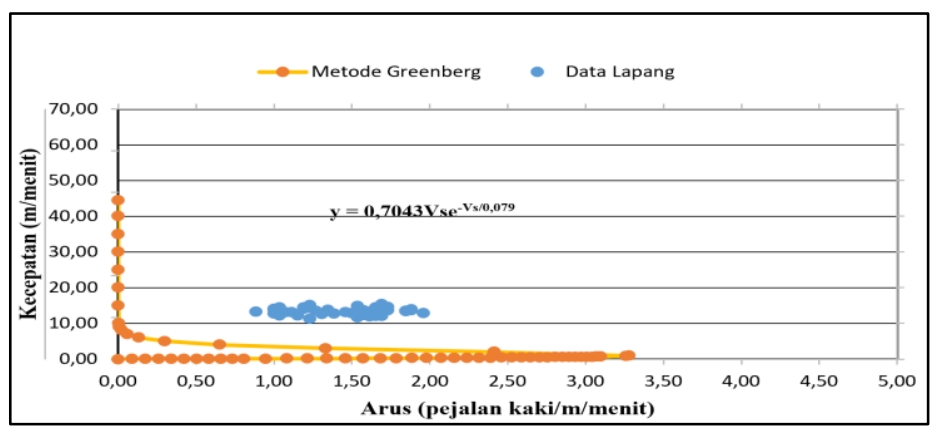

Gambar 9 Hubungan Arus (Q) dengan Kecepatan (Vs)

Dengan menggunakan metode Greenberg, dapat ditentukan karakteristik jalur pejalan kaki pada kondisi maksimum. Hasil yang diperoleh adalah bahwa kecepatan maksimum 
(Vm) adalah 12,68 m/min, arus maksimum Qm adalah 3,29 pejalan kaki/m/min, kepadatan maksimum (D) adalah 0,26 pejalan $\mathrm{kaki} / \mathrm{m}^{2}$, dan ruang maksimum (Sm) adalah 3,85 $\mathrm{m}^{2} /$ pejalan kaki.

\section{Tingkat Pelayanan Jalur Pejalan Kaki}

Standar tingkat pelayanan jalur pejalan kaki dapat dilihat pada Tabel 1. Standar tingkat layanan ini menunjukkan keterkaitan antara tingkat pelayanan dengan nilai yang didapat dari ruang, kecepatan dan arus pejalan kaki. Hasil analisis tingkat pelayanan dengan menggunakan pendekatan rata-rata ditunjukkan pada Tabel 2 dan hasil analisis tingkat pelayanan dapat dilihat pada Tabel 3 .

Tabel 1 Standar Tingkat Pelayanan Jalur Pejalan Kaki

\begin{tabular}{cccc}
\hline \multirow{2}{*}{$\begin{array}{c}\text { Tingkat } \\
\text { Pelayanan }\end{array}$} & $\begin{array}{c}\text { Ruang } \\
\left(\mathrm{m}^{2} / \text { pejalan kaki) }\right.\end{array}$ & $\begin{array}{c}\text { Arus dan Kecepatan Diharapkan } \\
(\mathrm{m} / \mathrm{min})\end{array}$ & $\begin{array}{c}\text { Arus } \\
\text { (pejalan kaki/m/min) }\end{array}$ \\
\hline A & $\geq 12$ & $\geq 79$ & $\leq 6,5$ \\
B & $\geq 4$ & $\geq 76$ & $\leq 23$ \\
C & $\geq 2$ & $\geq 73$ & $\leq 33$ \\
D & $\geq 1,5$ & $\geq 69$ & $\leq 46$ \\
E & $\geq 0,5$ & $\geq 46$ & $\leq 82$ \\
F & $<0,5$ & $<46$ & Bervariasi \\
\hline
\end{tabular}

Sumber: National Research Council (1994)

Tabel 2 Hasil Evaluasi Berdasarkan Nilai Rata-rata

\begin{tabular}{lc}
\hline \multicolumn{1}{c}{ Uraian } & Tingkat Pelayanan \\
\hline Kecepatan rata-rata $(\mathrm{V})$ & $\mathrm{E}$ \\
Arus rata-rata $(\mathrm{Q})$ & $\mathrm{A}$ \\
Ruang rata-rata $(\mathrm{S})$ & $\mathrm{A}$ \\
\hline
\end{tabular}

Pada Tabel 3 ditunjukkan bahwa berdasarkan metode Greenshields dan metode Greenberg, tingkat pelayanan jalur pejalan kaki di Jalan Braga pada waktu puncak adalah C. Kecepatan pejalan kaki tidak menjadi prioritas penilaian, karena meskipun kecepatan mendapat nilai rendah, tetapi Jalan Braga merupakan daerah untuk orang berjalan-jalan atau berwisata, sehingga pejalan kaki cenderung tidak berjalan dengan cepat.

Tabel 3 Hasil Evaluasi Berdasarkan Metode Greenshields dan Metode Greenberg

\begin{tabular}{lcc}
\hline \multirow{2}{*}{ Uraian } & \multicolumn{2}{c}{ Tingkat Pelayanan } \\
\cline { 2 - 3 } & Greenshields & Greenberg \\
\hline Kecepatan maksimum $(\mathrm{Vm})$ & $\mathrm{E}$ & $\mathrm{F}$ \\
Arus Maksimum $(\mathrm{Qm})$ & $\mathrm{B}$ & $\mathrm{A}$ \\
Ruang maksimum $(\mathrm{Sm})$ & $\mathrm{C}$ & $\mathrm{B}$ \\
\hline
\end{tabular}

\section{KESIMPULAN}

Pada studi ini dilakukan evaluasi tingkat pelayanan jalur pejalan kaki di Jalan Braga, Bandung. Data kondisi eksisting Jalan Braga, Bandung adalah bahwa lebar jalur 
pejalan kaki antara 2,5 m higga $3 \mathrm{~m}$. Pada jalur pejalan kaki ini terdapat pot tanaman, tiang listrik, kursi taman, pohon, lampu penerangan, bollard, serta barang toko dan pedagang kaki lima setempat yang mengambil lahan jalur pejalan kaki, sehingga lebar jalur efektif yang terkecil adalah $1,3 \mathrm{~m}$.

Karakteristik pejalan kaki di jalur pejalan kaki di Jalan Braga Kota Bandung berdasarkan metode Greenshields adalah bahwa kepadatan maksimum (Dm) adalah 0,54 pejalan kaki $/ \mathrm{m}^{2}$, kecepatan maksimum $(\mathrm{Vm})$ pejalan kaki adalah $31,57 \mathrm{~m} / \mathrm{min}$, arus maksimum $(\mathrm{Qm})$ adalah 16,92 pejalan kaki/menit/m, dan ruang $(\mathrm{Sm})$ pada jalur pejalan kaki adalah $1,85 \mathrm{~m}^{2} /$ pejalan kaki. Sedangkan berdasarkan metode Greenberg diperoleh kepadatan maksimum (Dm) adalah 0,26 pejalan kaki/m², kecepatan maksimum (Vm) adalah 12,68 $\mathrm{m} / \mathrm{min}$, arus maksimum $(\mathrm{Qm})$ adalah 3,29 pejalan kaki/menit/m, dan ruang $(\mathrm{Sm})$ pada jalur pejalan kaki $3,85 \mathrm{~m}^{2} /$ pejalan kaki.

Tingkat pelayanan jalur pejalan kaki pada waktu puncak berdasarkan kecepatan adalah $\mathrm{E}$ dan $\mathrm{F}$, tetapi berdasarkan arus dan ruangtingkat pelayanan ini bervariasi. Karena Jalan Braga merupakan kawasan wisata di Kota Bandung, kecepatan tidak merupakan prioritas penilaian. Berdasarkan metode Greenshiels dan metode Greenberg, tingkat pelayanan jalur pejalan kaki di Jalan Braga, Bandung, adalah C.

\section{DAFTAR PUSTAKA}

Departemen Pekerjaan Umum. 1990. Petunjuk Perencanaan Trotoar Nomor 007/T/BNKT. Jakarta.

Departemen Pekerjaan Umum. 1991. Perencanaan Teknis Fasilitas Pejalan Kaki. Jakarta. Gumelar, R. 2011. Studi Evaluasi Pelayanan Pedestrian Pada Jalan Urip SumuharjoPanglima Sudirman. Tugas Akhir, Universitas Pembangunan Nasional. Surabaya.

Julianto, E.N. 2010. Hubungan Antara Kecepatan, Volume Dan Kepadatan Lalu Lintas Ruas Jalan Siliwangi Semarang. Jurnal Teknik Sipil dan Perencanaan, 12 (2): 151-160.

Kementerian Pekerjaan Umum 2014. Peraturan Menteri Pekerjaan Umum No. 03/PRT/M/ 2014, tentang Pedoman Perencanaan, Penyediaan, Dan Pemanfaatan Prasarana Dan Sarana Jaringan Pejalan KakidDi Kawasan Perkotaan. Jakarta.

Mannering, F.L. dan Washburn. S.S. 2013. Princple of Highway Engineering And Traffic Analysis Fifth Edition. Australia.

National Research Council. 1994. Highway Capacity Manual Special, Report 209, Third Edition. Washington, D.C.

Preiser, W.F.E., Vischer, J.C., dan White, E.T. 1991. Design Intervention, Toward a More Humane Architecture. New York, NY: Van Nostrand Reinhold.

Suryawan, I.K.E.W., Negara, I.N.W., dan Wikrama, A.A.N.A.J. 2010. Pemilihan Model Hubungan Antara Volume, Kecepatan, Dan Kerapatan Jalan Dalam Kota (Studi Kasus: Jalan Ahmad Yani, Denpasar). Jurnal Ilmiah Teknik Sipil, 19 (1): 10-17. 